\section{Values and Sexual Behaviour in Central and Eastern Europe}

\author{
ROBIN GOODWIN \\ Brunel University, $U K$
}

ANU REALO,

University of Tartu, Estonia

ANNA KWIATKOWSKA

Warsaw School of Advanced Social Psychology, Poland

ALEXANDRA KOZLOVA

St Petersburg University, Russia

LAN ANH NGUYEN LUU

Eotvos Lorand University, Hungary

GEORGE NIZHARADZE

Academy of Sciences, Georgia

ACKNOWLEDGEMENTS. This project was supported by a research grant from the Research Support Scheme operated by the Soros Foundation, Prague. We would like to thank Ahto Külvet and Andu Rämmer for their help in collecting data and Grazyna WieczorkowskaNejtardt, Shalom Schwartz and two anonymous reviewers for their advice during the development of this article.

COMPETING INTERESTS: None declared.

ADDRESS. Correspondence should be directed to: ROBIN GOODWIN, Department of Human Sciences, Brunel University, Uxbridge UB8 3PH, UK. [email: Robin. Goodwin@brunel.ac.uk].
Journal of Health Psychology Copyright $(2002$ SAGE Publications London, Thousand Oaks and New Delhi, [1359-1053(200201)7:1]

Vol 7(1) 1-000; 020651

\section{Abstract}

Despite the profusion of social cognitive models for the prediction of sexual behaviour, we have only limited knowledge as to the role of individual values in predicting risky sexual activity. This study assessed the relationship between a recently developed value structure and sexual behaviour in the context of rising HIV infection in central and eastern Europe. Five hundred and three respondents (business people, doctors and nurses) from Estonia, Georgia, Hungary, Poland and Russia completed Schwartz's Portrait Values Questionnaire (Schwartz, Melech, Lehmann, Burgess, \& Harris, 2001) and reported their condom use, partnership history and record of sexual disease. Results indicated that values had a moderate but consistent relationship with sexual behaviour, with riskier sexual activity reported by those high on Openness to Change,

Hedonism and Self-

Enhancement. These findings are discussed in the context of the need for culturally sensitive interventions in order to tackle the growing HIV epidemic in this region.

\section{Keywords}

Keywords to follow, keywords to follow, keywords to follow, keywords to follow ??? 
THE HIV/AIDS EPIDEMIC is a relatively recent phenomenon in eastern Europe, only beginning in the early 1990s. However, World Health Organization (WHO) AIDS surveillance figures indicate a rapid growth in both HIV and AIDS in eastern Europe over the past five years with central and eastern Europe now showing the world's steepest HIV curve (European Centre for Epidemiological Monitoring of AIDS in Europe, 1999; Joint United Nations Programme on HIV/AIDS, 2000b). In the towns and cities surrounding Moscow, HIV infection increased five times in the first nine months of 1999 (Joint United Nations Programme on HIV/AIDS, 2000a) and new infections during the year 2000 were higher than in all previous years of the epidemic combined (Joint United Nations Programme on HIV/AIDS, 2000b), Meanwhile the geographical location of other, less infected nations in the former Soviet Bloc on drug routes, as well as high rates of prostitution and of population movement, raises the prospect of rapid increase in infection across this region (de Jong, Tsagarelli, \& Schouten, 1999; Dehne, Khodakevich, Hamers, \& Schwartlander, 1999). Unfortunately, however, as yet we have little information regarding the social and cultural forces that underlie the spread of the epidemic in this rapidly changing part of the world (Barnett, Whiteside, Khodakevich, Kruglov, \& Steshenko, 2000).

A number of social structural factors have been suggested to explain the rapid rise of HIV infection in these countries. These explanations cite the growth of temporary sexual partnerships as a means of economic survival (Kalichman, 1998; Renton, Borisenko, Tichonova, \& Akovian, 1999; Rhodes, Ball et al., 1999), the development of high-risk sexual practices as a coping response to a stressful environment (Kalichman, 1998) and a persisting gender role socialization that has led to an acceptance of sexual violence and increased infection risk (Horne, 1999; Kalichman et al., 2000). However, there has been little empirical research examining the individual-level factors that might underlie sexual behaviour in this region. In particular, there is little understanding of those transsituational values that might serve to increase the differential spread of the epidemic among groups in this region (Dehne et al., 1999).

In the research reported here, we focus on individual differences in values and their relationship to sexual behaviour in five central and eastern European countries: Estonia, Georgia, Hungary, Poland and Russia. These countries vary not only in the spread of the epidemic in each nation but in political structure, influence and nature of the religion(s) practised and level of economic investment and growthall factors likely to have important implications for the spread of sexual infection (Borisenko, Tichonova, \& Renton, 1999; Parker, Easton, \& Klein, 2000). Estonia and Georgia are both parts of the former Soviet Union with low rates of HIV infection (fewer than 50 cases of AIDS had been reported in both countries at the beginning of our study in 1998). In Hungary and Poland, rates of infection are relatively low and stable, with little evidence of a marked increase in AIDS incidence (Poland: 794 AIDS cases, Hungary: 328 AIDS cases; European Centre for Epidemiological Monitoring of AIDS in Europe, 1999b). In contrast, the Russian Federation has seen a marked escalation in the HIV epidemic (Joint United Nations Programme on HIV/AIDS, 2000b; Kalichman et al., 2000), with such infection accompanied by dramatic increases in a range of other sexual disease (Joint United Nations Programme on HIV/AIDS, 1998b; Kalichman et al., 2000).

\section{Values and sexual behaviour}

Over the last decade, Shalom Schwartz and his team have developed a quasi-circumplex model of 10 values whose structure has been verified in more than 70 cultures, including the five included in our present study (Schwartz, 1992; Schwartz \& Sagiv, 1995). Defining values as 'desirable transsituational goals ... that serve as guiding principles in the life of a person or other social entity' (Schwartz, 1994, p. 21), this model has now been applied to a wide range of applications, including the study of outgroup perception (Sagiv \& Schwartz, 1995), the process of democratization (Schwartz \& Sagie, 2000) and practices in the workplace (Schwartz, 1999a). The model can be organized along two dimensions: (1) Openness to Change (independent thought and action, reflected in concepts of Autonomy) versus Conservatism (Conformity, Tradition and Security); and (2) SelfTranscendence (Universalism and Benevolence) 
versus Self-Enhancement (Achievement and Power). A final value type, Hedonism, is related to both Openness to Change and Self-Enhancement. Table 1 provides a brief definition of these values and Figure 1 presents the quasi-circumplex model. From an ecological perspective (Schwartz, Bardi, \& Bianchi, in press) this emphasis on values (rather than personality) is particularly useful for the analysis of societies undergoing rapid social transition, during which rapid changes in environmental conditions might be expected to result in considerable individual variations in values across time (Rohan, 2000; Rokeach, 1973). Such manifest transformations in ecological conditions have, of course, been a notable characteristic of this region since the fall of communism (Goodwin, 1998).

In this study, we build on previous work on values by Schwartz and his team, as well as previous research on sensation seeking and sexual adventurism, to suggest a number of hypotheses concerning the relationship between values and sexual behaviour. ${ }^{1}$

Hypothesis 1: Respondents who score highly on the Openness to Change dimension stress a pleasurable, varied and daring life. Such individuals might also be expected to be 'sensation seekers' who seek intense and novel sensations and experiences and are willing to take high levels of sexual risk for the sake of such experiences (Donohew et al., 2000; Geis \& Gerrad, 1984; McCormick, Izzo, \& Folcik, 1985; Zuckerman, 1994). Here we predict that those who score highly on the Openness to Change value dimension will have had more sexual encounters and will report more sexual disease than those emphasizing the Conservatism dimension (Conformity, Tradition and Security).

Hypothesis 2: Those scoring high on Hedonism also seek pleasure and sensual gratification for themselves, and embrace risk taking. Just as sexual adventurists are likely to be at high risk of HIV infection (Kalichman, 1998), we might also expect those high on hedonism to report more sexual disease and more multiple partnerships.

Hypothesis 3: Finally, the relationship between Self-Enhancement/Self-Transcendence and sexual behaviour is likely to be complex and gender specific. Sociobiological research has argued that a strong emphasis on social prestige and power among men can act as an important marker for female mate attraction, but that such a preference is less likely for males seeking female partners (Buss, 1989; Feingold, 1992). We therefore anticipate a positive correlation between self-enhancement and number of partners among our male respondents.

\section{Method}

\section{Research participants}

Altogether, 503 persons participated in this study. One hundred participants were recruited in Hungary, Poland and Russia, 101 in Estonia and 102 in Georgia. Participants were recruited primarily through medical schools or business training courses taught by the research team or their colleagues. Some 86 percent of those approached agreed to participate.

Business people $(n=251$, mean age $=32.4, \mathrm{SD}$ $=7.2,47$ percent male) were selected as a highly mobile group whose lifestyle and relatively high incomes permits them to engage in particular higher-risk activities (Barnett et al., 2000). Members of such a group are likely to visit sex workers (Wellings, Fields, Johnson, \& Wadsworth, 1994) and thus to be at high risk of HIV infection (Towianska, Rozlucka, \& Dabrowski, 1992). Given the poor levels of screening and general hospital conditions in many of the nations under consideration (Renton et al., 1999), medics were also selected as a relatively high-risk group, and also represent a population whose knowledge and representations of HIV are potentially highly influential in the broader society (NascimentoSchulze, Garcia, \& Arruda, 1995). Medical workers were doctors $(n=145$, mean age $=34.7$, $\mathrm{SD}=6.3,61$ percent male $)$ and nurses $(n=98$, mean age $=33.2, \mathrm{SD}=7.3,7$ percent male) from across the five countries. All respondents were aged between 25 and 57 years (mean age $=33.2$, $\mathrm{SD}=7.1$ ), the age groups in which there is the greatest proportion of reported AIDS cases in the five countries studied (Joint United Nations Programme on HIV/AIDS, 1998b). Respondents were generally well educated, with 62 percent having completed university, although only 38 percent of nurses had continued beyond the 'special secondary' level of education. Polish respondents were overwhelmingly Catholic (93 percent of the sample) and a further 53 percent of Hungarian respondents were also Catholics. The Orthodox Church was strongly represented 


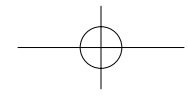

JOURNAL OF HEALTH PSYCHOLOGY 7(1)

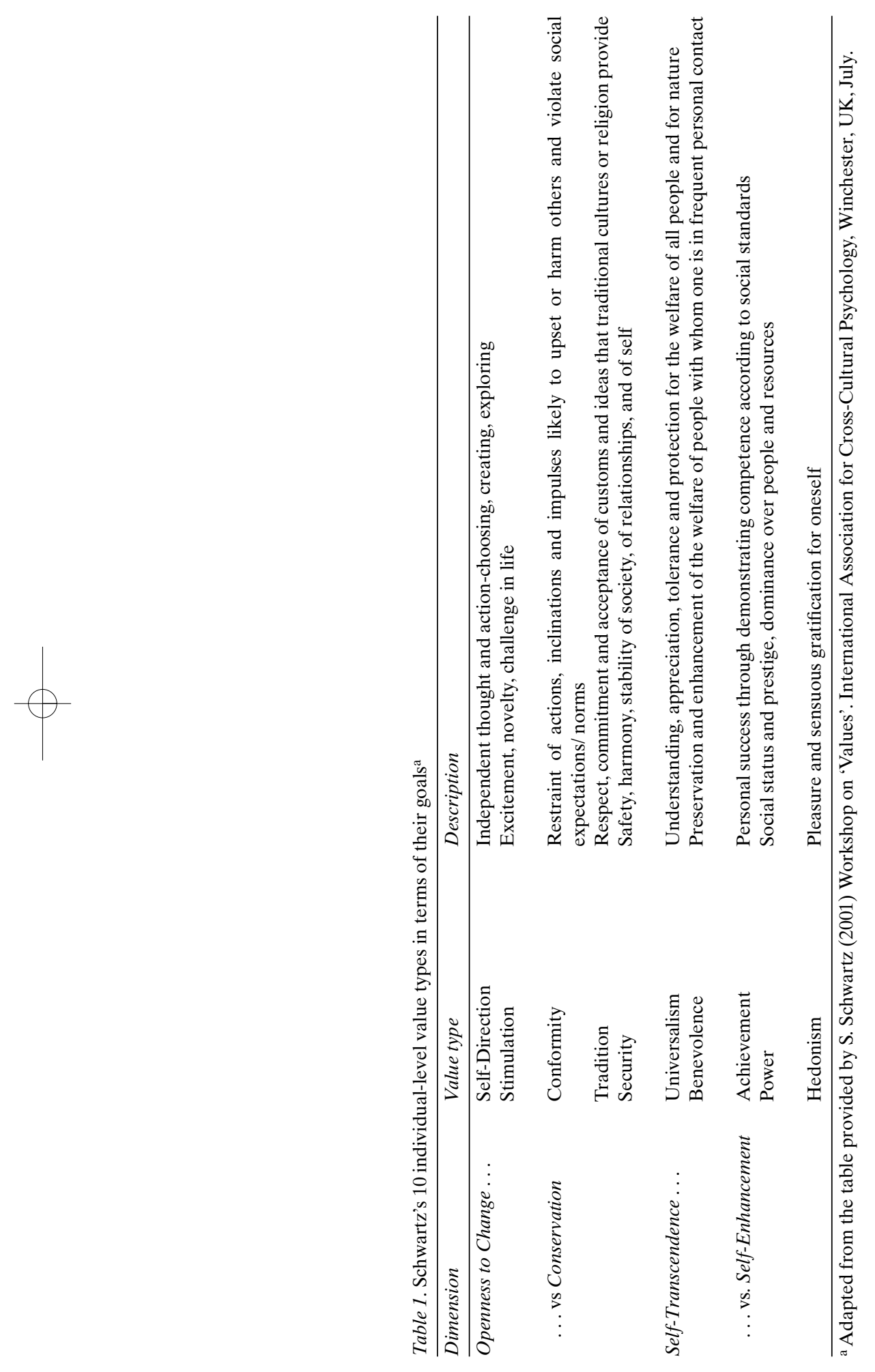




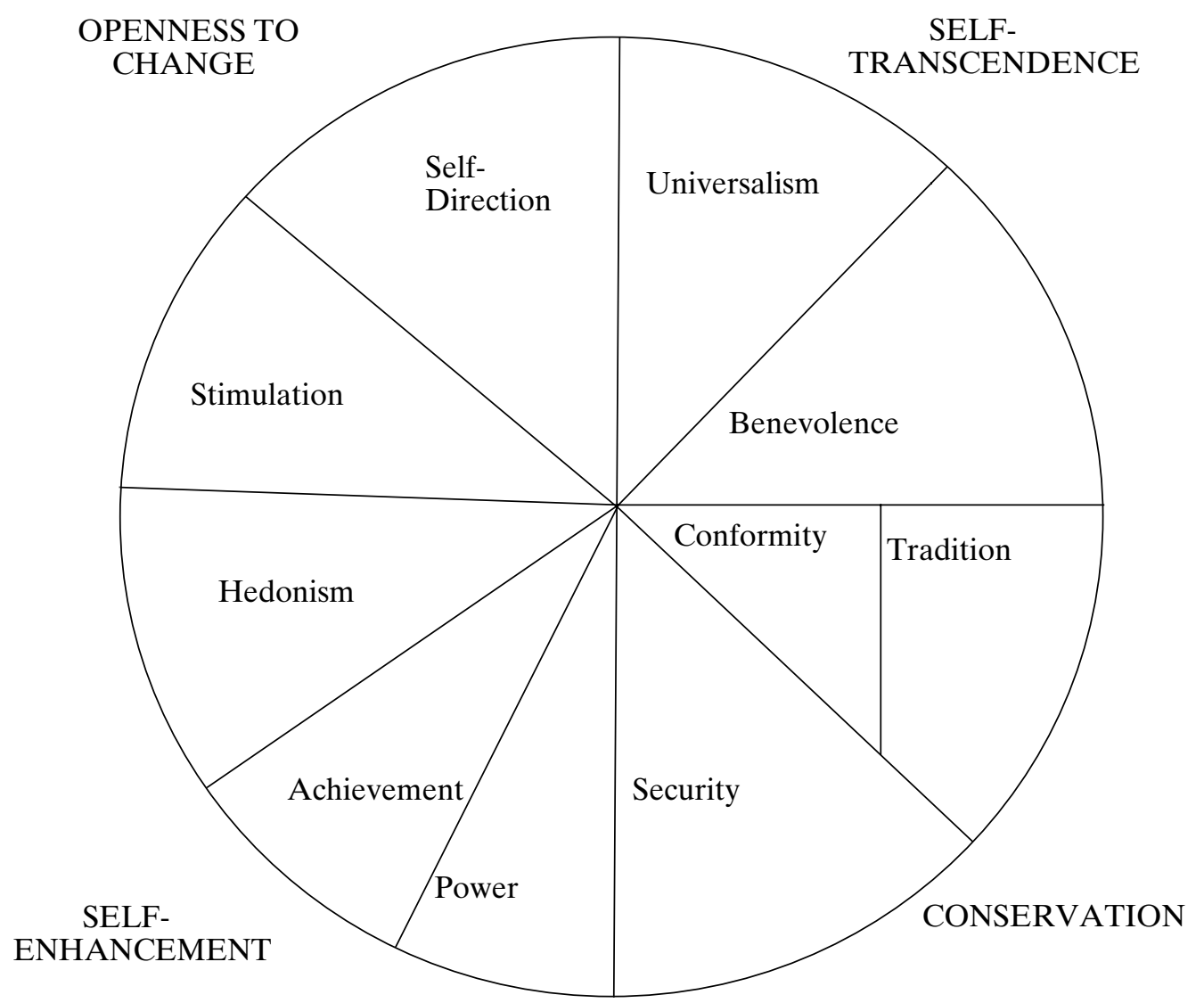

Figure 1. Theoretical model of 10 motivational types of values. Adapted from 'Value priorities and subjective well-being: direct relations and congruity effects', L. Sagiv and S. Schwartz, 2000, European Journal of Social Psychology, 30, p. 180. Copyright 2000 by John Wiley \& Sons. Adapted with permission of the author.

in Georgia (96 percent of respondents were Georgian Orthodox) and Russia (75 percent of participants were Russian Orthodox). Seventyone percent of the Estonian respondents were not religious.

\section{Procedure}

Data were collected by the principal researcher in each country and their medical colleagues during 1999 in the capital cities of Hungary, Russia, Georgia and Estonia (Budapest, Hungary; Tbilisi, Georgia; Moscow, Russia; Tallinn, Estonia). Additional data were also collected in the relatively high infection areas of eastern Poland (Chodynicka, Serwin, JanczyloJankowska \& Waugh, 1999) and in St Petersburg, Russia (Kalichman et al., 2000) and in the towns of Kutaisi and Batumi (Georgia) and Tartu (Estonia).

All participants completed the same scales measuring Schwartz's values and sexual behaviour either at their place of work or during business training workshops. Respondents also indicated their age, sex, nationality, educational level, occupation and religious affiliation. To deal with possible cultural biases in question design and implementation procedures (Goodwin, 1996), items were discussed in a group meeting in Estonia and reworded to maximize cultural sensitivity (Werner \& Campbell, 1970). Questionnaires were then back-translated by bilingual translators (cf. Brislin, 1980) and revised versions checked for accuracy. Finally, scales were piloted on a subsample of 10 


\section{JOURNAL OF HEALTH PSYCHOLOGY 7(1)}

medical workers and 10 entrepreneurs in each culture to remove any further ambiguities prior to the main data collection.

\section{Measures}

Values were assessed using a version of Schwartz's Portrait Values Scale (Schwartz, Melech, Lehmann, Burgess, \& Harris, 2001). Respondents were asked to consider 29 descriptions of imaginary individuals and asked 'How much is the person in the description like you?' responding on six-point scales ranging from Not like me at all to Very much like me. Scale items were divided into the 10 value types specified in Table 1 then formed into the dimensions Openness to Change versus Conservatism and SelfTranscendence versus Self-Enhancement. A typical item, assessing Conformity, provided a description of a person for whom 'It is important to him to be polite to other people all the time. He believes he should always show respect to his parents and to older people'. Overall internal reliability for the value dimensions was reasonable: the standardized Cronbach alphas were .79 (Self-Enhancement), .66 (Self-Transcendence), .71 (Openness to Change), .74 (Conservation) and .68 (Hedonism). Differences in scale use scores on scale items were adjusted for each culture to allow for culture-specific variations in scale usage and further adjusted at the individual level by using individual's total scores to centre our data or as a covariate in our analyses (Schwartz, 1999b).

To indicate sexual behaviour, respondents reported whether they had ever had sexual intercourse, the number of sexual partners they had had over the past week/month/six months, and their frequency of condom use over the past six months (on a four-point scale ranging from never to always). They also indicated whether they had ever had a sexually transmitted diseases (STD, scored on a binary scale). Additional binary variables were created for the presence (absence) of multiple partnerships over the previous six months (RISKY) and the presence (absence) of multiple partnerships accompanied by low (high) condom usage (VRISKY).

\section{Results}

\section{Sexual behaviour across the five nations}

Ten percent of the sample reported that they were not sexually active over the past six months. Sixteen percent of the complete sample reported more than one sexual partner a month, 7 percent more than one partner a week. Seventy-two percent of the sexually active sample reported that they had had only one regular sexual partner over the previous six months. The largest number of mean partners was reported by the Russian respondents (2.4 over six months) and the lowest by the Poles in our sample (1.2 over six months). Business people $(M=1.8)$ recorded more sexual partners than the other two occupational groups during this six-month period ( $M$ for doctors $=1.7$, nurses $=1.1$ ). Seventeen percent of the sample had had a previous STD, with a sexual disease reported more frequently by Russian, Georgian and Estonian respondents (25-27 percent) than by Hungarian ( 5 percent) or Polish ( 2 percent) respondents $\left(\chi^{2}(4)=42.3, p<.001\right)$. Business people (23 percent) or doctors (15 percent) rather than nurses (4 percent) $\left(\chi^{2}(2)=16.7, p<\right.$ $.001)$ were more likely to report STDs.

\section{Values and sexual behaviour}

Table 2 provides raw correlations for the 10 individual value types and two dimensions, number of partners over the previous six months and the binary variables (RISKY, VRISKY and STD) described above. ${ }^{2}$ Our findings indicate relatively small but consistent correlations between values and sexual behaviour with those values on the left-hand side of the quasi-circumplex model (Self-Direction, Stimulation, Hedonism, Achievement and Power) predictors of generally riskier sexual behaviour and those on the right-hand side (Universalism, Benevolence, Conformity, Tradition and Security) indicators of safer sexual practices. Number of partners over the previous six months was positively correlated to the individual values of Power, Achievement, Hedonism and Stimulation and negatively correlated to values of Universalism, Benevolence, Conformity, Tradition and Security. Eight of these 10 values (all but Conformity and Self-Direction) were significant indicators of the combined variable VRISKY 
GOODWIN ET AL.: VALUES AND SEXUAL BEHAVIOUR

Table 2. Pearson moment-product correlations for values and sexual behaviour

\begin{tabular}{lcccc}
\hline Value dimensions and types & STD & No. of partners & RISKY & VRISKY \\
\hline Openness to Change & $.22^{* *}$ & $.22^{* *}$ & $.22^{* *}$ & $.18^{* *}$ \\
Self-Transcendence & $-.22^{* *}$ & $-.25^{* *}$ & $-.29^{* *}$ & $-.27^{* *}$ \\
Universalism & $-.16^{* *}$ & $-.23^{* *}$ & $-.30^{* *}$ & $-.26^{* *}$ \\
Benevolence & -.08 & $-.18^{* *}$ & $-.18^{* *}$ & $-.19^{* *}$ \\
Conformity & $-.11^{* *}$ & $-.12^{* *}$ & $-.11^{*}$ & -.08 \\
Tradition & $-.15^{* *}$ & $-.22^{* *}$ & $-.17^{* *}$ & $-.13^{* *}$ \\
Security & $-.09^{* *}$ & $-.13^{* *}$ & $-.18^{* *}$ & $-.17^{* *}$ \\
Power & $.24^{* *}$ & $.19^{* *}$ & $.22^{* *}$ & $.23^{* *}$ \\
Achievement & $.14^{* *}$ & $.16^{* *}$ & $.18^{* *}$ & $.15^{* *}$ \\
Hedonism & $.10^{* *}$ & $.18^{* *}$ & $.24^{* *}$ & $.23^{* *}$ \\
Stimulation & $.19^{* *}$ & $.17^{* *}$ & $.21^{* *}$ & $.16^{* *}$ \\
Self-Direction & $.15^{* *}$ & .08 & .05 & .02
\end{tabular}

STD = sexually transmitted disease; No. of Partners = number of partners over the previous six months; RISKY = presence (absence) of multiple partnerships over the previous six months; VRISKY = presence (absence) of multiple partnerships accompanied by low (high) condom usage. Upper bounds for point serial correlations were .67 (STD), .74 (RISKY) and .61 (VRISKY)

(i.e. multiple partnerships and low condom use). Those higher in Power, Achievement, Hedonism, Stimulation and Self-Direction were also significantly more likely to indicate a history of STD: those higher in Universalism, Conformity, Tradition and Security were less likely to report such disease.

Above we hypothesised that those high on the dimension Openness to Change (Hypothesis 1) and high on Hedonism (Hypothesis 2) would have had more sexual encounters and a greater exposure to STD. Analyses of variance, with an individual's total scores as the covariate, confirmed our expectations: those highest on risk (i.e. those who had multiple partners over the previous six months and only rarely used a condom $)$ were higher on Hedonism $(F[1,456]=$ $26.5, p<.001)$ and Openness to Change $(F[1,445]$ $=16.5, p<.001)$. This finding was strongest in Poland for both the Openness to Change dimension $(r[88]=.31, p=.003)$ and Hedonism scores $(r[88]=.41, p<.001)$. 'High-risk' individuals were also higher on Self-Enhancement $(F[1,452]$ $=36.3, p<.001)$, but, contrary to Hypothesis 3 , this pattern was evident for both sexes $(F[1,232]$ $=14.1, p<.001$ for men; $F[1,217]=10.0, p<.002$ for women). Sexual diseases were also more likely to be reported by those scoring high on Hedonism $(F[1,483]=6.5, p<.001)$, Openness to Change $(F[1,472]=27.2, p<.001)$ and Achievement and Power $(F(1,479)=20.1, p<$ $.001)$ with this pattern strongest in the Russian sample ( $r=.21, .32$ and .40 , respectively).

\section{Multivariate analyses}

To what extent do key demographic factors (country, occupation and sex) explain the sexual behaviours analysed in this study, and to what degree do values further add to our understanding of these behaviours? To address this we conducted a series of multivariate analyses to examine the impact of the combination of demographic factors (country, occupation, sex) and Schwartz's values on reported sexual behaviour. An analysis of covariance, with nation, occupation and sex as independent variables, the three value dimensions and total values score as covariates, and the number of sexual partners over six months as the dependent variable explained 24 percent of the variance $\left(R^{2}=.29: R^{2}\right.$ adjusted $=.238)$ and revealed significant effects for nationality $(F[4,411]=4.7, p<.001)$, SelfTranscendence $(F[1,411]=9.9, p<.002)$ and sex $(F[1,411]=6.1, p<.02)$. Those high on achievement and power were more likely to report a higher number of partnerships, while Russian respondents and male participants reported more sexual partners (males overall reported a mean of 2.1 partners over six months compared to 1.1 by female respondents).

Finally, we performed hierarchical logistic regressions on the three binary dependent variables created and described above (STD, RISKY and VRISKY). Each analysis used the forward stepwise method using the Likehood Ratio test for variable removal and entering first demographic variables (Block 1: country, sex, 
JOURNAL OF HEALTH PSYCHOLOGY 7(1)

occupation) then Schwartz's values centred around the individual's mean score for all values (Block 2). Table 3 reports relevant betas, Wald statistics and partial correlations for these three dependent variables.

For the prediction of multiple partnerships over six months (RISKY), and multiple partnerships and low condom use (VRISKY), our best models allowed us to accurately classify 79.5 percent and 83.3 percent of cases respectively $\left(\chi^{2}[2]=24.6, p<.001\right.$ for RISKY, $\chi^{2}[2]=23.5, p$ $<.001$ for VRISKY). Nationality, Hedonism and Self-Transcendence were all significant contributors in these final models, with Russians reporting significantly riskier sexual behaviour, as did those high on Hedonism and those low on Self-Transcendence. We accurately classified 84.2 percent of cases for the variable STD $\left(\chi^{2}[1]\right.$ $=11.06, p<.001)$, with Nationality and Openness to Change significant contributors to our final model. Consistent with the other findings reported above, a history of sexual disease was most frequently reported by our Russian respondents, male participants and those high on the Openness to Change dimension.

\section{Discussion}

The rapid spread of the HIV epidemic has led to the development of a number of psychological models for the prediction of sexual behaviour, such as the Health Belief Model (Rosenstock, Strecher, \& Becker, 1994), the theory of Planned Behaviour (Ajzen, 1988) and the AIDS Risk Reduction Model (Catania, Kegeles, \& Coates, 1990). The great majority of these models have focused on the social cognitive factors that underlie sexual behaviours (Kalichman, 1998) and have paid less attention to the role of values on sexual activity (Breakwell, Millward, \& Fife-Schaw, 1994; Joffe, 1996; Rhodes, Stimson et al., 1999). In this study, we examined the relationship between 10 value types, condom use, history of sexual disease and number of sexual partners in an area of rising HIV infection. Our data demonstrated that values were moderate but significant predictors of reported sexual behaviours, with riskier sexual activity reported by those who were Open to Change, Hedonistic and high on Self-Enhancement. When considered alongside other important demographic variables these findings offer us important new insights into the implications of individual values for sexual behaviours both in this region and-potentially-across the world.

Table 3. Summary of final model logistic regressions

\begin{tabular}{llll}
\hline Predictor variables & Wald & $p<($ Wald $)$ & $R$ \\
\hline RISKY: multiple partnerships over six months & & .23 \\
Nation & 30.31 & .001 & .14 \\
Sex & 10.37 & .01 & .07 \\
Nation * Sex & 3.86 & .05 & -.01 \\
Occupation * Sex & 2.06 & .15 & .15 \\
Hedonism & 11.34 & .001 & -.09 \\
Self-Transcendence & 5.71 & .02 & \\
& & & .21 \\
VRISKY: multiple partnership with low condom use & & .00 \\
Nation & 21.31 & .001 & -.14 \\
Nation * Occupation & .28 & .59 & .18 \\
Nation * Sex & 7.59 & .01 & -.08 \\
Hedonism & 11.83 & .001 & \\
Self-Transcendence & 4.33 & .04 & .28 \\
STD: history of STD & & & -.12 \\
Nation & 32.46 & & .10 \\
Sex & 6.49 & .001 & -.16 \\
Occupation * Sex & 5.04 & .01 & .03 \\
Openness to Change & 10.59 & .001 & \\
\hline$R=$ partial correlation & & 59 & \\
\hline
\end{tabular}

$R=$ partial correlation index STD = sexually transmitted disease 
Reported sexual activity varied by both occupation and nation. Most notably, sexual activity was highest among our Russian respondents. While the high rates of multiple partnership were perhaps not surprising given the currently high rates of sexual disease in this country, the occurrence of high-risk behaviour among the highly qualified and knowledgeable doctors in this nation did surprise our research team (more than 20 percent of Russian doctors reported having more than one sexual partner per week). In contrast, our Polish sample reported very few multiple partnerships and low rates of sexual disease. Poland can be characterized as a 'familistic' culture (Fukuyama, 1995) where family-centred social networks may serve to inhibit casual sexual activity and, in a separate analysis of family-orientated collectivism which included these five countries, Realo (2000) found Poland to be the most family-orientated of these nations. Religion may be an additional factor in sexual behaviour in this culture (Weinberg, Lottes, \& Shaver, 2000): nearly all our Polish respondents were Catholics with the Catholic Church in Poland having recently played a highly visible-if somewhat controversial-role in the promotion of safer sexual practices in this nation (Danziger, 1996). Future analyses should consider degree of religiosity, rather than just religious group nominated, as a further potential predictor of sexual activity in this region (Weinberg et al., 2000).

There were, of course, a number of important limitations to our present investigation. Comparisons with other compatible data sets on cultural values in this region (Schwartz \& Bardi, 1997), and with studies of sexual activity in Poland (World Health Organization, 1997), Hungary (Szilagyi, 1996) and Georgia (Kachkachishvili, 1999), suggest that our data are consistent with the findings of larger, more representative studies. ${ }^{3}$ Further research should aim to include a wider, more representative sample, and should, in particular, ensure the inclusion of adolescent drug users, now a significant high-risk group in this region (Kalichman, 1998; Rhodes, Stimson et al., 1999). Our research was conducted in only selected cities in five countries in this region: further research should strive to incorporate a wider range of geographical locations, both urban and rural, and should include other countries at risk from the spread of the epidemic, particularly additional states from the former Soviet Union. Finally, we employed only a limited range of questions, all of which required the self-reporting of sensitive information. In future research other data sources (such as focus groups and media analyses) could be usefully employed when investigating the role of both individual and cultural values in the spread of this epidemic (Joffe, 1996).

The number of HIV/AIDS cases in central and eastern Europe is still not large compared to many other afflicted regions of the world. As a consequence it should still be possible to limit the size of the epidemic in this region (Kalichman et al., 2000). We believe that our findings emphasize the need to attract and hold the attention of target audiences by developing dynamic programmes targeted towards the psychological profile of these audiences (Donohew et al., 2000). Subcultures that stress values such as power and stimulation need to be targeted with attractive interventions that allow for the values of these groups, and we need to anticipate the reaction of such subcultures to more conservative 'traditional' health messages. These subcultural groups are likely to include not only stereotypical 'youth cultures' but less frequently studied subsamples, such as business people and some groups of medical professionals. Such interventions need to be 'culture-specific' so that, for example, the possible 'filtering' effect on absorbing health messages of a strong emphasis on autonomy is recognized when designing campaigns focused on manipulating societal or peer pressure. Finally, media interventions need to be constructed within the context of enduring economic realities, where the adoption of safer sexual behaviour may threaten not only romantic ties but also very economic survival (Hobfoll, 1998). Any successful assault on this epidemic will therefore require both recognition of the role played by these values and their interrelationship with the ecological realities of the region.

\section{Notes}

1. The work reported in this article was part of a multistage project which included semi-structured interviews, free-associations on HIV and a media 


\section{JOURNAL OF HEALTH PSYCHOLOGY 7(1)}

analysis in each country. Further details of the full project are available from the first author.

2. STD, RISKY and VRISKY are point serial correlations whose upper bound is set by the distribution of the binary variable. As this distribution was skewed for these variables the upper bounds for our correlations were less than 1.00. The upper bounds of these correlations are reported in Table 2.

3. Comparable individual-level data for values have not previously been reported for these five countries but, in a previous investigation of the culturallevel values of students and teachers in central and eastern Europe, Schwartz and Bardi (1997) examined a set of seven values organized along three dimensions: Egalitarian-Hierarchy, HarmonyMastery and Autonomy-Embeddedness. Following a country-level standardization procedure described by Schwartz (1999b) we compared rank order scores for the five countries across the two data sets. Consistent with Schwartz and Bardi's (1997) findings, Georgians and Poles were the most collectivist (embedded) respondents in our sample and Russians the most hierarchical. Egalitarianism was also highest among Georgians and Estonians, as evident in Schwartz and Bardi's data. However, Russians scored relatively highly on Mastery in our sample. Further details of these comparisons, and contrasts with the data sets on sexual behaviour reported by the World Health Organization (1997), Szilagyi (1996) and Kachkachishvili (1999) are available from the first author.

\section{References}

Ajzen, I. (1988). Attitudes, personality, and behavior. Chicago: Dorsey.

Barnett, T., Whiteside, A., Khodakevich, L., Kruglov, Y., \& Steshenko, V. (2000). The HIV/AIDS epidemic in Ukraine: Its potential social and economic impact. Social Science and Medicine, 51, 1387-1403.

Borisenko, K. K., Tichonova, L. I., \& Renton, A. M. (1999). Syphilis and other sexually transmitted infections in the Russian Federation. International Journal of STD and AIDS, 10, 665-668.

Breakwell, G. M., Millward, L. J., \& Fife-Schaw, C. (1994). Commitment to 'Safer' sex as a predictor of condom use among 16-20 year olds. Journal of Applied Social Psychology, 24, 189-217.

Brislin, R. (1980). Translation and content analysis of oral and written material. In H. Triandis \& J. Berry (Eds.), Handbook of cross-cultural psychology (Vol. 2) Boston: Allyn \& Bacon.

Buss, D. M. (1989). Sex differences in human mate preferences: Evolutionary hypotheses tested in 37 cultures. Behavioral and Brain Sciences, 12, 1-14.

Catania, J. A., Kegeles, S. M., \& Coates, T. J. (1990).
Towards an understanding of risk behavior: An AIDS risk reduction model (ARRM). Health Education Quarterly, 17, 53-72.

Chodynicka, B., Serwin, A. B., Janczylo-Jankowska, M., \& Waugh, M. A. (1999). Epidemiology of syphilis and gonorrhoea in eastern Poland in the years 1988-1997. International Journal of STD and AIDS, 10, 680-684.

Danziger, R. (1996). Compulsory testing for HIV in Hungary. Social Science and Medicine, 43, 1199-1204.

de Jong, W., Tsagarelli, T., \& Schouten, E. (1999). Rapid assessment of injection drug use and HIV in the Republic of Georgia. Journal of Drug Issues, 29, 843-859.

Dehne, K. L., Khodakevich, L., Hamers, F. F. \& Schwartlander, B. (1999). The HIV/AIDS epidemic in Eastern Europe: recent patterns and trends and their implication for policy-making. AIDS, 13, 741-749.

Donohew, L., Zimmerman, R., Cupp, P. S., Novak, S., Colon, S., \& Abell, R. (2000). Sensation seeking, impulsive decision-making, and risky sex: Implications for risk-taking and design of interventions. Personality and Individual Differences, 28, 1079-1091.

European Centre for Epidemiological Monitoring of AIDS in Europe. (1999a). HIV/AIDS Surveillance in Europe, Quarterly Report, June.

European Centre for Epidemiological Monitoring of AIDS in Europe. (1999b). HIV/AIDS Surveillance in Europe, Quarterly Report, November.

Feingold, A. (1992). Gender differences in mate selection preferences: A test of the parental investment model. Psychological Bulletin, 112, 125-139.

Fukuyama, F. (1995). Trust. London, Penguin.

Geis, B. D., \& Gerrad, M. (1984). Predicting male and female contraceptive behaviour: A discriminant analysis of groups high, moderate, and low in contraceptive effectiveness. Journal of Personality and Social Psychology, 46, 669-680.

Goodwin, R. (1996). A brief guide to cross-cultural research. In J. Howath (Ed.), Psychological research (pp. 78-94). London: Routledge.

Goodwin, R (1998). Invited programme overview. Personal relationships and social change: The 'realpolitik' of cross-cultural research in transient cultures. Journal of Social and Personal Relationships, 15, 227-247.

Hobfoll, S. E. (1998). Ecology, community and AIDS. American Journal of Community Psychology, 26, 133-144.

Horne, S. (1999). Domestic violence in Russia. American Psychologist, 54, 55-61.

Ingram, M. (1996). Russia is on brink of AIDS epidemic. British Medical Journal, 313, 252.

Joffe, H. (1996). AIDS research and prevention: A 
social representation approach. British Journal of Medical Psychology, 69, 169-190.

Joint United Nations Programme on HIV/AIDS (1998a). Report on the global HIV/AIDS epidemic. June.

Joint United Nations Programme on HIV/AIDS. (1998b). Epidemiological fact sheets on HIV/AIDS and sexually transmitted diseases. [On-line] Available: www.who.int/emc/diseases/hiv/Global_ Reports.html. June.

Joint United Nations Programme on HIV/AIDS (1999). AIDS epidemic update. December 1999 [On-line] Available: www.who.int/emc/diseases/ hiv/Global_Reports.html. December.

Joint United Nations Programme on HIV/AIDS (2000a). Report on the global HIV/AIDS epidemic [On-line] Available: www.unaids.org/epidemic update/report/index.html. June.

Joint United Nations Programme on HIV/AIDS (2000b) Aids epidemic explodes in eastern Europe. Press release [On-line]. Available: www.unaids.org/ wac/2000/wad00/files/ ruepr.html. December.

Kachkachishivili, Y. (1999). Analysis of sociological survey on reproductive health related problems among residents of Tblisi. The New Paradigms, 3 , 125-129.

Kalichman, S. C. (1998). Preventing AIDS: A sourcebook of behavioral interventions. Mahwah, NJ: Lawrence Erlbaum.

Kalichman, S. C., Kelly, J. A., Sikkema, K. J., Koslov, A. P., Shaboltas, A., \& Granskaya, J. (2000). The emerging AIDS crisis in Russia: Review of enabling factors and prevention needs. International Journal of STD and AIDS, 11, 71-75.

McCormick, N., Izzo, A., \& Folcik, J. (1985). Adolescents' values, sexuality, and contraception in a rural New York county. Adolescence, 20, 385-395.

Nascimento-Schulze, C., Garcia, Y. F., \& Arruda, D. C. (1995). Health paradigms, social representations of health and illness and their central nucleus. Papers on Social Representations, 4, 187-198.

Parker, R. G., Easton, D., \& Klein, C. H. (2000). Structural barriers and facilitators in HIV prevention: A review of international research. AIDS, 14(Suppl. 1), S22-S32.

Realo, A. (2000). Relationship between collectivistic attitudes and sexual behavior. In A. M. Chodynicka \& G. Mizera (Eds.), Program and the book of abstracts of the 15th congress of the International Association for Cross-Cultural Psychology (p. 158). Poland: Pultusk.

Renton, A. M., Borisenko, K. K., Tichonova, L. I., \& Akovian, V. A. (1999). The control and management of sexually transmitted diseases: A comparison of the United Kingdom and the Russian Federation. International Journal of STD and AIDS, 10, 659-664.
Rhodes, Y., Ball, A., Stimson, G. V., Kobyshcha, Y., Fitch, C., Pokrvsky, V., Bezruchenko-Novachuk, M., Burrows, D., Renton, A., \& Andrushchak, L. (1999). HIV infection associated with drug injecting in the newly independent states, eastern Europe: The social and economic context of epidemics. Addiction, 94, 1323-1336.

Rhodes, T., Stimson, G. V., Crofts, N., Ball, A., Dehne, K., \& Khodakevich, L. (1999). Drug injecting, rapid HIV spread, and the 'risk environment': Implications for assessment and response. AIDS(13 Suppl. A), S259-S269.

Rohan, M. J. (2000). A rose by any name? The values construct. Personality and Social Psychology Review, 4, 255-277.

Rokeach, M. (1973). The nature of human values. San Francisco: Jossey-Bass.

Rosenstock, M., Strecher, V., \& Becker, M. (1994). The health belief model and HIV risk behavior change. In R. DiClemente \& J. Peterson (Eds.), Preventing AIDS: Theories, methods and behavioral interventions (pp. 5-24). New York: Plenum.

Sagiv, L., \& Schwartz, S. H. (1995). Value priorities and readiness for out-group social contact. Journal of Personality and Social Psychology, 69, 437-448.

Schwartz, S. H. (1992). Universals in the content and structure of values: Theoretical advances and empirical tests in 20 countries. In M. P. Zanna (Ed.) Advances in experimental social psychology (Vol. 25) (pp. 1-65). New York: Academic Press.

Schwartz, S. H. (1994). Are there universal aspects in the structure and contents of human values? Journal of Social Issues, 50, 19-45.

Schwartz, S. H. (1997). Values and culture. In D. Munro, S. Carr, \& J. Schumaker (Eds.), Motivation and culture (pp. 69-84). New York: Routledge.

Schwartz, S. H. (1999a). A theory of cultural values and some implications for work. Applied Psychology: An International Review, 48, 23-47.

Schwartz, S. H. (1999b). Cultural dimensions and value types. Workshop presented at the IACCP Conference, Graz, Austria.

Schwartz, S. H., \& Bardi, A. (1997). Influences of adaptation to communist rule on value priorities in eastern Europe. Political Psychology, 18, 385-410.

Schwartz, S. H., Melech, G., Lehmann, A., Burgess, S., \& Harris, M. (2001). Extending the cross-cultural validity of the theory of basic human values with a different method of measurement. Journal of CrossCultural Psychology, 32, 519-542.

Schwartz, S. H., \& Sagiv, L. (1995). Identifying culture specifics in the content and structure of values. Journal of Cross-Cultural Psychology, 26, 92-116.

Schwartz, S. H., \& Sagie, G. (2000). Value consensus and importance: A cross-cultural study. Journal of Cross-Cultural Psychology, 31, 465-497. 


\section{JOURNAL OF HEALTH PSYCHOLOGY 7(1)}

Szilagyi, E. (1996). Az AIDS egeszsegugyi, prevencios, kulturalis es tarsadalomtudomanyi megkozelitese. NEVI: Budapest.

Towianska, A., Rozlucka, E., \& Dabrowski, J. (1992). Prevalence of HIV anti-bodies in maritime workers and in other selected population groups in Poland. Bulletin of the Institute of Maritime and Topical Medicine in Gdynia, 43, 19-24.

Weinberg, M. S., Lottes, I., \& Shaver, F. M. (2000). Sociocultural correlates of permissive sexual attitudes: A test of Reiss' hypotheses about Sweden and the United States. Journal of Sex Research, 37, 44-52.

Wellings, K., Fields, J., Johnson, A. M., \& Wadsworth,
J. (1994). Sexual behaviour in Britain. London: Penguin.

Werner, O., \& Campbell, D. T. (1970). Translating, working through interpreters and the problem of decentering. In R. Naroll \& R. Cohen (Eds.), A handbook of cultural anthropology. New York: American Museum of Natural History.

World Health Organization. (1997). Sexual and prohealth behaviour in Poland in relation to HIV and AIDS. Warsaw: WHO.

Zuckerman, M. (1994). Behavioral expressions and biosocial bases of sensation seeking. Cambridge, UK: Cambridge University Press. 